\title{
Ser e Tornar-se Psicoterapeuta Parte I: Diálogo entre Experiências Pessoais e Profissionais
}

\author{
Being And Becoming a Psychotherapist Part I: Dialogue \\ Between Personal and Professional Experiences \\ Ser y Tornarse Psicoterapeuta Parte I: Diálogo Entre \\ Experiencias Personales y Profesionales
}
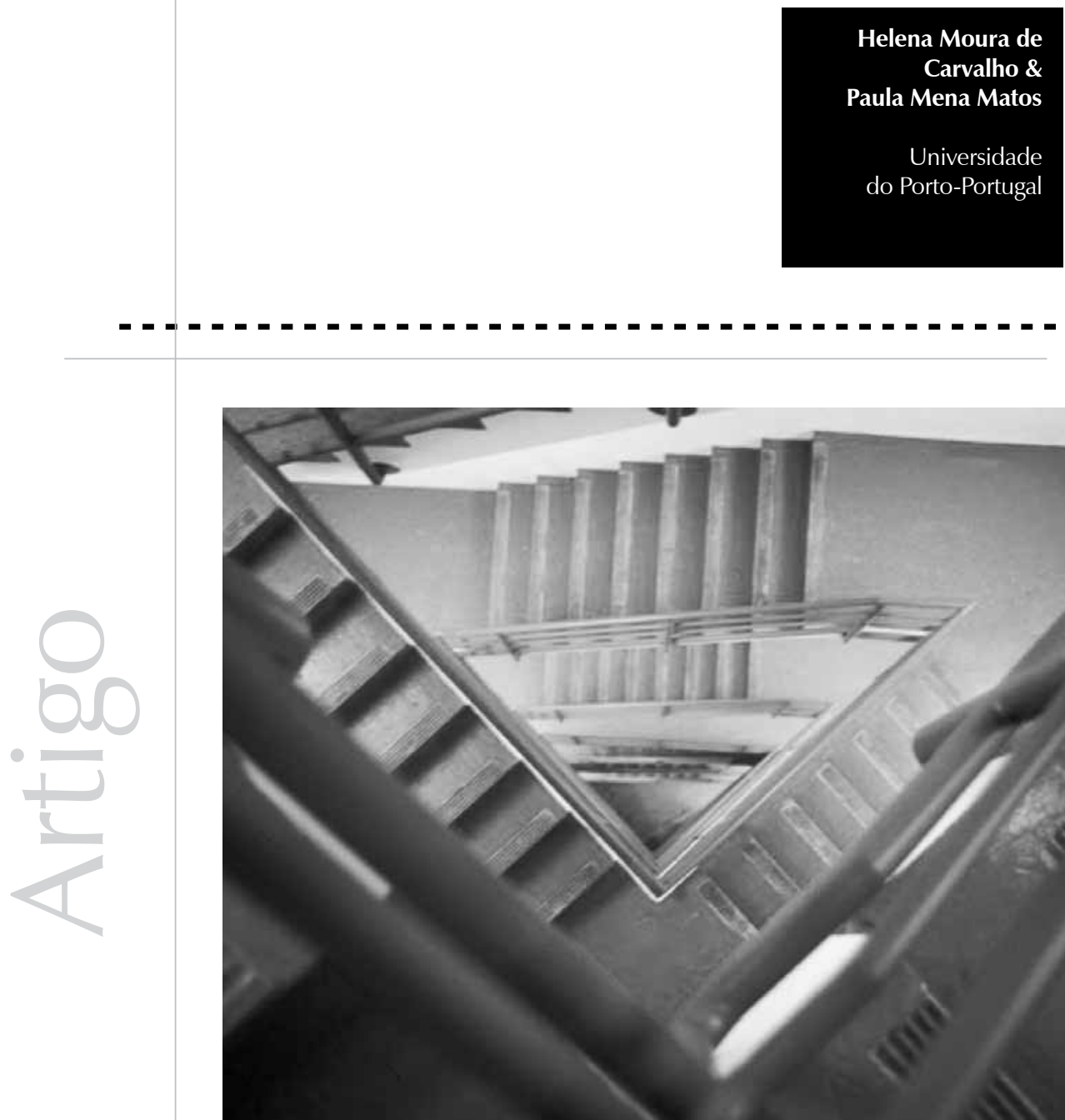

Helena Moura de Carvalho (Bolseira de doutoramento pela Fundação para a Ciência e Tecnologia (SFRH/ BD/22333/2005).

Trabalho realizado no âmbito do projecto da Fundação para a Ciência e TecnologiaPTDC/PSI/65416/2006 
"As we strive to better serve our clients, we may find that we can learn important lessons from patterns and processes in our own lives" (Radeke \& Mahoney, 2000,

"Eu sou um

bocadinho

de todos os meus clientes (...) quando os clientes vão fazer psicoterapia, não deviam pagar tudo, uma parte, nós é que devíamos pagar a eles!"

(Psicoterapeuta entrevistado, 2006)

Resumo: O psicoterapeuta tem sido considerado um elemento de primordial importância para o sucesso da psicoterapia no entanto, o estudo das suas características pessoais e profissionais tem sido negligenciado na investigação. O objetivo do presente artigo é analisar as narrativas de 20 psicoterapeutas experts (peritos) de diferentes orientações teóricas (cognitivo-comportamental, construtivista, humanista, psicanalítica e sistémica) sobre o seu desenvolvimento pessoal e profissional no decurso da prática clínica. Os dados foram recolhidos através de uma entrevista semiestruturada e foram analisados em uma perspetiva construtivista da grounded theory. Na análise emergiram dois grandes temas. Serão apresentados aqui os resultados do primeiro tema analisado, relativo às experiências relacionais do âmbito pessoal e profissional que contribuíram para o desenvolvimento dos psicoterapeutas. O tema organizador das entrevistas sublinha a importância do diálogo e da coerência entre o self pessoal e profissional na compreensão do desenvolvimento do psicoterapeuta. Palavras-chave: Estudo qualitativo. Desenvolvimento profissional. Psicoterapeutas. Desenvolvimento pessoal.

Abstract: The psychotherapist has been considered an element of major importance for the success of therapy, however the study of his/her personal and professional characteristics has been neglected in research. The purpose of this work is to analyze the narratives of 20 psychotherapists experts from different theoretical orientations (behavioral-cognitive, constructivist, humanistic, psychoanalytic and systemic) on their personal and professional development during clinical practice. Data were collected through a semi-structured interview and analyzed in a constructive perspective of grounded theory. In the analysis two main themes emerged. In this article are presented the results of the first theme, relating to experiences of personal and professional context that contributed to the development of psychotherapists. The organizing theme of the interviews emphasized the importance of dialogue and the consistency between the personal and professional self-understanding of the development of the psychotherapist. Keywords: Qualitative study. Professional development. Psychotherapists. Personal development.

Resumen: El psicoterapeuta ha sido considerado un elemento de primordial importancia para el éxito de la psicoterapia; no obstante, el estudio de sus características personales y profesionales ha sido negligenciado en la investigación. El objetivo del presente artículo es analizar las narrativas de 20 psicoterapeutas experts (peritos) de diferentes orientaciones teóricas (cognitivo del comportamiento, constructivista, humanista, psicoanalista y sistémica) sobre su desarrollo personal y profesional en el transcurso de la práctica clínica. Los datos fueron recogidos a través de una entrevista semi-estructurada y fueron analizados en una perspectiva constructivista de la grounded theory. En el análisis emergieron dos grandes temas. Serán presentados aquí los resultados del primer tema analizado, relativo a las experiencias relacionales del ámbito personal y profesional que contribuyeron para el desarrollo de los psicoterapeutas. El tema organizador de las entrevistas subraya la importancia del diálogo y de la coherencia entre el self personal y profesional en la comprensión del desarrollo del psicoterapeuta.

Palabras clave: Estudio cualitativo. Desarrollo profesional. Psicoterapeutas. Desarollo personal.

A investigação científica em psicoterapia remonta ao início do séc. XX, e o seu trajeto tem sido desenhado pelos desafios inerentes à própria evolução da Psicologia. Desde a procura positivista de afirmação da Psicologia como ciência, passando pelo questionamento da eficácia de Eysenck (1952) até o paradigma da equivalência (veredicto do pássaro DoDo), que se assiste a um debate apaixonado acerca dos processos e mecanismos subjacentes aos resultados e à especificidade do encontro terapêutico.

O estudo das características dos psicoterapeutas é quase tão antigo como a investigação em psicoterapia (Orlinsky, et al., 1999). Apesar da sua venerável história, assistiu-se, nas últimas duas décadas, a uma subvalorização desse componente na investigação em detrimento dos estudos realizados com os modelos psicoterapêuticos (Beutler, et al., 2004). Tal poderá dever-se ao facto de a investigação se centrar no estudo das terapias como conjunto de métodos, técnicas e procedimentos que são eficazes por si só no tratamento de desordens psicológicas e psiquiátricas, sendo a influência dos elementos pessoais ou dos processos subjetivos da experiência humana e das relações entendidos como fonte de erro a ser eliminada ou controlada na investigação (Orlinsky \& Rønnestad, 2005). Essa tentativa de laboratorizar/manualizar a investigação em psicoterapia, nomeadamente através da 
atribuição de variáveis parasitas à pessoa do psicoterapeuta, é posta em causa por investigações em que psicoterapeutas da mesma orientação teórica, que usavam a mesma psicoterapia manualizada e que eram treinados, monitorizados e supervisionados no mesmo contexto produziam diferentes resultados (Castonguay, Goldstein, Wiser, Raue, \& Hayes, 1996). Outras investigações e relatos autobiográficos relevaram a importância das características pessoais do psicoterapeuta, nomeadamente dos seus valores e filosofias pessoais (Vasco \& Dryden, 1994; Wilson, 1993), dos seus problemas e perturbações pessoais (e.g. Atwood \& Stolorow, 1993; Chasen, 1996) e das suas histórias de vinculação (Black, Hardy, Turpin, \& Parry, 2005; Sauer, Lopez, \& Gormley, 2003) na escolha das orientações teóricas, técnicas, metodologias de intervenção e características relacionais. Ahn e Wampold (2001), baseados em uma revisão de estudos sobre eficácia terapêutica, afirmam que a variabilidade dos resultados psicoterapêuticos era melhor explicada por características pessoais do psicoterapeuta do que por componentes específicos do tratamento. Muito recentemente, Reupert (2006), no seu artigo The Counsellor's Self in Therapy: an Inevitable Presence, ressalta que, apesar do reconhecimento de psicoterapeutas e investigadores de diferentes inspirações teóricas de que o psicoterapeuta traz mais para a psicoterapia do que a sua formação profissional, não se sabe ainda o que os psicoterapeutas trazem pessoalmente para os seus clientes ou como as suas qualidades e características se relacionam com os processos e os resultados psicoterapêuticos, quer positiva, quer negativamente. Nos últimos anos, com o intuito de suprimir o hiato da investigação nesse domínio, têm surgido estudos que sublinham a importância da adoção de uma perspetiva desenvolvimental e abrangente dos mecanismos subjacentes à mudança no psicoterapeuta. Destacamos os estudos desenvolvidos por Shovholt e Ronnestad (1995, 2003), assentes em uma metodologia qualitativa, que analisam o desenvolvimento dos psicoterapeutas com diferentes orientações teóricas e com diferentes graus de experiência, e o estudo internacional organizado por membros da Society for Psychotherapy Research (SPR Collaborative Research Network) acerca das características, práticas e experiências de psicoterapeutas de diferentes países, cujos resultados foram publicados recentemente (Orlinsky \& Rønnestad, 2005) e aos quais daremos especial atenção no presente estudo. Em Portugal, o número de estudos publicados é ainda mais escasso (e.g., Vasco, 1992; Vasco \& Dryden, 1997; Magalhães, 2008) revelando-se, assim, da maior importância proceder a estudos mais aprofundados das características dos psicoterapeutas e dos processos de mudança subjacentes ao seu desenvolvimento com impacto na prática psicoterapêutica.

O objetivo do estudo aqui apresentado é relevar as representações e as significações de psicoterapeutas reconhecidos (designados por experts ou peritos) de diferentes orientações teóricas e práticas acerca das experiências e dos momentos que consideraram determinantes no seu desenvolvimento profissional. A escolha de psicoterapeutas peritos deve-se ao facto de procurarmos explorar narrativas reflexivas das trajetórias desenvolvimentais dos psicoterapeutas e de a investigação sugerir que psicoterapeutas experientes e reconhecidos em diferentes áreas da saúde mental informant rich cases - constituem uma fonte importante na identificação de variáveis mais salientes (Patton, 1990) das características de psicoterapeutas que contribuem para a 
eficácia terapêutica (Jennings \& Skovholtz, 1999). Nesta análise, não pretendemos, no entanto, desenhar uma trajetória desenvolvimental dos psicoterapeutas, mas relevar um entendimento relacional da vivência de experiências psicoterapêuticas e extrapsicoterapêuticas no desenvolvimento do psicoterapeuta.

Este estudo foi realizado no âmbito de uma investigação mais alargada cujo objetivo geral é o estudo das dimensões da história pessoal, profissional e desenvolvimental do psicoterapeuta que concorrem para explicar o estilo pessoal (Fernandez-Álvarez, Garcia, LoBianco, \& Corbella, 2003) e, em particular, do modo como o psicoterapeuta estabelece e significa a relação terapêutica.

\section{Metodologia}

\section{Participantes}

A estratégia para a seleção da amostragem é considerada intencional (Patton, 1990), na medida em que procurámos selecionar psicoterapeutas reconhecidos no âmbito da prática psicoterapêutica e provenientes de contextos teóricos e práticos diversificados. Para a identificação dos psicoterapeutas informant rich cases (Patton, 1990), utilizámos a técnica da nomeação por pares (peer nomination), em que nove psicoterapeutas de diferentes orientações identificaram colegas que consideravam bons psicoterapeutas e aos quais recorreriam em caso de psicoterapia pessoal. Foram selecionados 23 psicoterapeutas de diferentes orientações teóricas e instituições acolhedoras que reuniam maior consenso na nomeação. Esses psicoterapeutas exerciam igualmente atividades de docência, supervisão no ensino superior em Psicologia e em associações ou sociedades de psicoterapia portuguesas de distintos pontos geográficos do país (e.g. Braga, Coimbra, Lisboa e Porto).
Os participantes foram recrutados através de contacto telefónico e via e-mail, e, dos 23 psicoterapeutas contactados, 20 aceitaram participar no estudo. As idades dos psicoterapeutas variam entre 35 e 77 anos $(M=50,35$ anos; $D P=9,95)$, e os anos de experiência, entre os 10 e os 44 anos $(M=21,4$ anos; $D P=8,79) .11$ psicoterapeutas são do sexo feminino, e 9 do sexo masculino. Relativamente ao background profissional, 16 dos psicoterapeutas entrevistados são psicólogos, 3 psiquiatras e 1 médico de clínica geral. Quanto às orientações teóricas, 4 psicoterapeutas identificamse predominantemente com o modelo cognitivo-comportamental (cc), 5 com o construtivista (c), 3 com o humanista (h), 4 com o psicanalítico (p) e 4 com o sistémico (s).

\section{Instrumento e procedimento}

No presente estudo, optou-se por utilizar uma metodologia qualitativa de investigação, visto ser esse o método considerado mais eficaz: (a) em fases exploratórias do processo de investigação (Patton, 1990), (b) na identificação de variáveis pouco referenciadas pela literatura (Stern, 1980) e (c) na obtenção de dados sobre fenómenos complexos tais como sentimentos, processos cognitivos e emoções difíceis de apreender através de metodologias de investigação mais convencionais (Strauss \& Corbin, 1990). Elaborou-se uma entrevista semiestruturada para o efeito, com 16 perguntas de resposta aberta, agrupadas em 7 temas centrais do processo desenvolvimental dos psicoterapeutas (Carvalho \& Matos, 2006), a referir:

1) motivações subjacentes à escolha de Psicologia/Psiquiatria; 2) motivações para ser psicoterapeuta; 3) desenvolvimento como psicoterapeuta (principais mudanças, agentes de mudança, estilo pessoal e características que permaneceram estáveis); 4) conceptualização atual do processo de mudança terapêutica e das principais 
O processo analítico

reflete, assim, a construção dos significados que os psicoterapeutas atribuem às suas experiências, por oposição a uma perspetiva positivista de descoberta da verdade

(Charmaz, 2000). características do psicoterapeuta que melhor contribuem para o processo terapêutico e para a promoção de mudança em psicoterapia; 5) impacto de ser psicoterapeuta na vida pessoal e relacional; 6) atuais dificuldades na prática e 7) aspirações futuras relativamente ao desenvolvimento como psicoterapeuta.

As entrevistas foram realizadas nos contextos de trabalho dos psicoterapeutas (à exceção de 2 entrevistas) entre outubro de 2006 e março de 2007, e tiveram uma duração média de 50 minutos. No início da entrevista, era explicado o objetivo geral do estudo, e era pedido aos participantes o seu consentimento para gravar a entrevista em formato áudio. Seguidamente, procedeu-se à transcrição in verbatim das entrevistas, tendo em conta a natureza discursiva e prosódica das narrativas dos psicoterapeutas.

\section{Estratégia de análise dos dados}

No decurso da recolha de dados, as entrevistas foram sucessivamente transcritas na sua totalidade e analisadas por ambas as autoras do estudo. Esse procedimento permitiu uma reflexão das questões do guião que poderiam ser reformuladas ou incluídas de forma a recolher dados importantes e que emergiam espontaneamente nas entrevistas. De seguida, procedeu-se à análise de dados através do método da grounded theory (Glaser \& Strauss, 1967; Strauss \& Corbin, 1990). A grounded theory, tal como o nome indica, consiste em um método de análise qualitativa que tem como objetivo a construção de teorias fundamentadas nos dados, através do recurso a um conjunto de procedimentos indutivos e sistemáticos (Strauss \& Corbin, 1990). Esse procedimento permitiu, em um primeiro momento, a recolha de secções do texto que expressavam diferentes significados e etapas do desenvolvimento do psicoterapeuta, na medida em que a mesma temática poderia ser explorada pelos participantes em diferentes questões.
De seguida, essas unidades de sentido foram organizadas em temas emergentes e categorias descritivas. Ao longo do processo de análise, as categorias hierarquicamente superiores e de complexidade crescente iam emergindo de acordo com a sua capacidade em agrupar os conceitos e as categorias anteriormente definidas. Trata-se de uma metodologia de abstração e complexidade crescente, dado que o método comparativo característico da grounded theory (Glaser \& Strauss, 1967; Strauss \& Corbin, 1990) exige uma permanente reformulação e reflexão dos dados anteriormente analisados. O processo de codificação e interpretação dos dados foi realizado em parceria pelas autoras, e periodicamente eram discutidas as categorias emergentes e os temas organizadores. A análise dos dados inscreve-se em uma perspetiva cíclica de combinação indutiva e dedutiva até a construção, pelo investigador, da narrativa da essência da experiência dos participantes, designada como core story (Charmaz, 2000; Strauss \& Corbin, 1990). O processo analítico reflete, assim, a construção dos significados que os psicoterapeutas atribuem às suas experiências, por oposição a uma perspetiva positivista de descoberta da verdade (Charmaz, 2000).

$\mathrm{Na}$ análise, emergiram dois grandes temas: (a) experiências relacionais e (b) etapas e mudanças do desenvolvimento do psicoterapeuta. Dadas as limitações de espaço de publicação e a natureza da análise, no presente artigo, serão apresentados os resultados do primeiro tema organizado em dois subtemas, a saber, (a) experiências relacionais no domínio profissional e (b) experiências relacionais no domínio pessoal que contribuíram para o desenvolvimento dos psicoterapeutas (vide Fig.1). De seguida, será apresentado o tema organizador ou história core identificado, a saber, o desenvolvimento do psicoterapeuta: diálogo e coerência entre self pessoal e profissional, visto ser o elemento que emerge da narrativa como mais 
representativo da forma como os psicoterapeutas atribuem significado à sua experiência e ao seu processo desenvolvimental, que, sendo transversal na análise preconizada, representa uma leitura síntese e integrada dos dois sub-temas supracitados do desenvolvimento do psicoterapeuta.

Tema

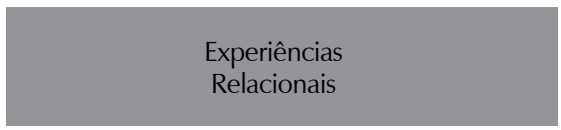

\begin{tabular}{|c|c|}
\hline Sub-temas & $\begin{array}{c}\text { Domínio da } \\
\text { vivência profissional }\end{array}$ \\
\hline \multirow[t]{3}{*}{$\begin{array}{l}\text { Categorias } \\
\text { e subcategorias }\end{array}$} & $\begin{array}{l}\text { Impacto + } \\
\text { - sentido de gratificação; } \\
\text { - acesso a dimensões } \\
\text { privilegiadas; } \\
\text { - natureza da ligação } \\
\text { emocional. }\end{array}$ \\
\hline & $\begin{array}{l}\text { Impacto - } \\
\text { - incapacidade de ajuda; } \\
\text { - desistências inesperadas } \\
\text { de clientes; } \\
\text { - dificuldades na relação } \\
\text { terapêutica; } \\
\text { - gestão dos limites da terapia; } \\
\text { - desgaste emocional. }\end{array}$ \\
\hline & $\begin{array}{l}\text { Validação dos factores } \\
\text { determinantes } \\
\text { - leitura colaborativa do } \\
\text { processo terapêutico; } \\
\text { - importância da qualidade } \\
\text { da relação terapêutica; } \\
\text {-pragmática de ajuda. }\end{array}$ \\
\hline
\end{tabular}

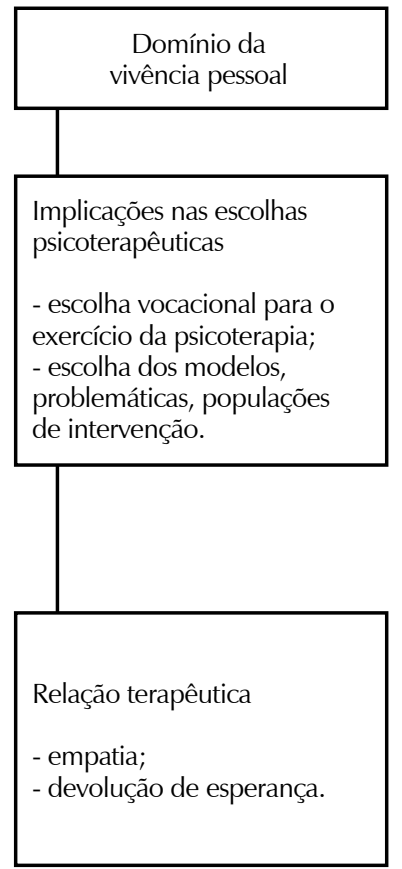

Figura 1. Organização do tema experiências relacionais do desenvolvimento do psicoterapeuta, sub-temas e categorias 
1 No sentido de auxiliar o leitor na identificação e na compreensão das narrativas transcritas, foi atribuído um código às citações onde constam três indicações: a primeira é relativa à orientação teórica (cC-cognitivo comportamental, c-constructivista, h-humanista, p-psicanalítica, s-sistémica), a segunda é relativa ao número de entrevistas dentro do mesmo modelo, e a terceira, relativa ao sexo do entrevistado ( $\mathrm{m}$-masculino e f-feminino). Por exemplo, (p1m) p corresponde à orientação psicanalítica, 1 , ao número do psicoterapeuta dentro da orientação psicanalítica, e m corresponde ao sexo masculino.
Dado que a análise qualitativa não se esgota na categorização e na codificação dos dados, mas estende-se ao processo de escrita, procuraremos apresentar essa coconstrução narrativa da experiência dos

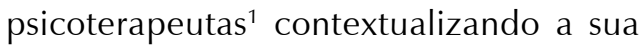
emergência através do recurso ao formato escrito e ao áudio das mesmas assim como às anotações do entrevistador sobre o espaço e a vivência dessa partilha de significados, algo que se poderá assemelhar a um contador de histórias que permanece consistente com a metodologia da grounded theory e da escrita científica social, visto que as histórias se organizam em torno de categorias conceptuais (Charmaz, 2000).

\section{Resultados}

Subtema 1: Experiências relacionais no domínio profissional que contribuíram para o desenvolvimento do psicoterapeuta

No domínio da prática psicoterapêutica, as experiências relatadas como mais marcantes surgem no contexto de interação com os clientes. A natureza relacional da psicoterapia é entendida pelos psicoterapeutas como pedagógica e transformativa no sentido em que a vivência partilhada da situação terapêutica se constitui enquanto espaço privilegiado para o seu desenvolvimento profissional. Nesse tema, emergiram três categorias:

1.1. experiências com impacto positivo e reforçador da prática; 1.2. experiências com impacto negativo na prática psicoterapêutica e 1.3. fatores validados pela experiência psicoterapêutica considerados determinantes no processo terapêutico.

\subsection{Experiências com impacto positivo e reforçador da prática}

São ressaltadas como tendo impacto positivo e reforçador da prática (a) experiências promotoras de um sentimento de gratificação pela ajuda prestada em situações de grande sofrimento e em que o psicoterapeuta percebe um sentido de utilidade na evolução do processo terapêutico, (b) experiências de acesso a dimensões privilegiadas da vivência humana através dos clientes e (c) a natureza da ligação emocional.

A percepção de sucesso no acompanhamento de casos avaliados como mais difíceis e geradores de maior ativação emocional nos psicoterapeutas (decorrente, entre outros aspetos, da experiência vicariante do sofrimento) são sentidas como reforçadoras do investimento na prática clínica, nomeadamente em fases iniciais do exercício da prática psicoterapêutica. Essas experiências podem ser tão marcantes que podem determinar o investimento, por parte do psicoterapeuta, em determinadas problemáticas e mesmo a permanência no exercício da psicoterapia. Um dos psicoterapeutas cita um caso de resolução difícil como marcador central da resolução da angústia derivada de expectativas desajustadas e ampliadas relativamente ao seu papel como psicoterapeuta e que o faziam questionar a continuidade da sua prática clínica $(\mathrm{c} 1 \mathrm{~m})$. Alguns processos são representados como marcos importantes na sinalização de transições entre fases desenvolvimentais distintas. Vejamos, por exemplo, o caso de uma psicoterapeuta que possui na sua carteira fotografias de uma cliente que foi considerada marco importante na sua capacidade de estabelecer a relação terapêutica (s1f), ou o caso de outro psicoterapeuta que ainda guarda o desenho, na sua parede de consultório, de um processo difícil e de grande ativação emocional (c1m).Os participantes também consideram que o acesso a dimensões consideradas privilegiadas da vivência do ser humano tem impacto positivo e reforçador na prática psicoterapêutica, nomeadamente, pelo testemunhar da capacidade combativa do sujeito, pelo interesse suscitado pelo filosofar 
(h1m) idiossincrático do cliente: "O que a psicoterapia tem de mais encantador é que você tem janelas para aquilo que as pessoas têm de mais interessante, que é a capacidade de se debaterem e de lutarem contra uma situação extremamente adversa" (c2m).

A natureza da ligação emocional que os psicoterapeutas afirmam estabelecer com determinados clientes e que determinam o acesso a material significativo na vivência do cliente são também considerados momentos marcantes na sua história como psicoterapeutas:

Os momentos (mais marcantes) são os momentos de ativação emocional dos pacientes ou quando são pessoas com aspetos de privação muito grandes ou de uma vinculação muito distante às figuras mais próximas, e que depois se vinculam a nós de uma maneira muito particular, e que nos têm em grande conta e em grande estima, e que depois se permitem, no espaço da consulta, às vezes certos tipos de ativação e de recordação de certas memórias, e procuramos trabalhar certos acontecimentos de vida que é quase um privilégio às vezes ter acesso a essas coisas (cc2m)

\subsection{Experiências com impacto negativo na prática psicoterapêutica}

Por outro lado, considera-se que têm impacto negativo na prática psicoterapêutica e no desenvolvimento do psicoterapeuta na medida em que podem condicionar o exercício da mesma: (a) a perceção da incapacidade de ajuda, nomeadamente quando associada a expectativas elevadas do poder do psicoterapeuta em proporcionar ajuda ao cliente, (b) as desistências da psicoterapia quando constituem surpresa e, por isso, são representadas como uma ameaça à capacidade de avaliação da evolução do processo terapêutico, (c) as dificuldades sentidas em estabelecer uma relação terapêutica de ajuda com determinados clientes e problemáticas, descrito por uma psicoterapeuta como acontecimento "terrível" (cc1f) e expressa na seguinte afirmação:

\begin{abstract}
Sentir que eles (os clientes) precisavam de ser ajudados, mas, por outro lado, desejar que não voltassem, porque era demasiado duro para mim aguentar (...) são consultas, além de dolorosas do ponto de vista humano, porque nós não conseguimos de facto distanciarmo-nos dessa situação, é estarmos sempre muito atentos a qualquer frase ou qualquer palavra que nós podemos dizer que pode ser interpretada de forma errada e, portanto, deitar tudo a perder (s2f)
\end{abstract}

Outras experiências avaliadas pelos psicoterapeutas como dotadas de impacto negativo na prática psicoterapêutica e no desenvolvimento do psicoterapeuta são: as (d) dificuldades sentidas na gestão dos limites da psicoterapia com os clientes, nomeadamente situações de assédio de clientes, de perseguição ou de aproximação para além dos limites da psicoterapia ou tentativas de manipulação em psicoterapia conjugal e, por último, (e) o desgaste emocional que a vivência relacional de situações dramáticas e a vivência de situações-limite de sofrimento humano possam provocar no psicoterapeuta, e que está patente na seguinte narrativa:

\footnotetext{
Nós temos que absorver muita emotividade negativa, isso passa por nós (...) Nós trazemos a voz dos pacientes conosco, portanto, as emoções ficam conosco e demoram horas a escorrer para fora do corpo, horas (...). Tocamos o absurdo da vida, ficamos ali com o absurdo ao colo e, às vezes, demoram horas até nos libertarmos disso (c2m)
}

Essas experiências são percebidas como marcantes do ponto de vista negativo do desenvolvimento do psicoterapeuta devido à dificuldade em gerir o seu tónus emocional, nomeadamente em momentos iniciais da prática psicoterapêutica. A prática supervisionada e a discussão interpares são representadas como momentos optimais para, 
por um lado, dar segurança e tranquilidade necessárias ao exercício da prática clínica, principalmente pela confrontação com novas perspetivas acerca da intervenção e, por outro lado, para auxiliarem os psicoterapeutas na gestão da carga emotiva suscitada no confronto com situações-limite de sofrimento humano, como exemplifica o relato abaixo:

Aquela partilha é quase como uma catarse, pronto, ok, deixa descarregar (...) nós é que trazemos aquela carga emocional, portanto, temos um colega com quem vamos descarregar e vamos falar e o que é que sentimos, o que é que pensamos, e as dúvidas que tivemos... isso ajuda imenso, parece que... ufa, saiu um fardo de cima das nossas costas (s2f)

\subsection{Fatores validados pela experiência psicoterapêutica considerados determinantes no processo psicoterapêutico}

A síntese e a integração das experiências decorrentes da prática psicoterapêutica parecem também contribuir para a validação dos fatores determinantes no processo de mudança psicoterapêutica, alguns dos quais já abordados na componente teórica da formação do psicoterapeuta, mas que são reforçados pela prática acumulada, a saber: (a) a importância da significação pessoal dos clientes acerca das suas problemáticas, o que nos remete para uma leitura colaborativa do processo terapêutico, tão bem expresso na seguinte afirmação a boa hipótese é a hipótese útil, não necessariamente a hipótese verdadeira! (s3f), (b) a importância da qualidade da relação terapêutica como fator determinante do processo, patente na seguinte afirmação:

No início, isso era apenas teoria, hoje é uma coisa que eu sei que é uma realidade porque a vivi, porque, ao longo destes anos, encontrei pessoas, casos mais difíceis, outros menos, mas em que eu descobri que, se eu criar as condições relacionais, essas pessoas são capazes de encontrar a melhor maneira de estar na vida (h2m)

Outro fator que emerge da prática acumulada e refletida é (c) o conhecimento da pragmática da ajuda, ou seja, o conhecimento emergente do acompanhamento de diversos clientes e das suas histórias psicoterapêuticas, que são preservados na memória do psicoterapeuta e se constituem enquanto importantes recursos na condução de novos processos psicoterapêuticos:

Eu já vivi caminhadas muito semelhantes às que estamos a fazer com outras pessoas, já fiz travessias muito complicadas com outras pessoas, e portanto, já fui o barqueiro de muita gente. E posso contar muitas histórias que têm muita validade clínica, que ajudam muito as pessoas a perceberem as suas experiências e a sentirem-se legitimadas nas suas dificuldades, portanto essa é, de facto, uma mais-valia importante e que não vem nos manuais, é a própria aprendizagem da pragmática da clínica (c2m)

Subtema 2: Experiências relacionais no domínio pessoal que contribuíram para o desenvolvimento do psicoterapeuta

No domínio das experiências pessoais do psicoterapeuta, foram sinalizados acontecimentos subjacentes a transições normativas e não normativas promotoras de mudança na forma de estar e de ser psicoterapeuta. São as tais luzes e sombras (s4f) do percurso pessoal, como nos diz uma participante e que se projetam no cenário da prática psicoterapêutica:

A pessoa vai amadurecendo, vai passando, ela própria, por fases importantes do seu ciclo de vida pessoal, conjugal, familiar; acho claramente que é um fator importantíssimo no amadurecimento de um psicoterapeuta e no crescimento de um psicoterapeuta (s4f).

Nesse subtema, emergiram duas categorias: 2.1. implicações nas escolhas psicoterapêuticas e 2.2. implicações na relação psicoterapêutica. 


\subsection{Implicações nas escolhas psicoterapêuticas}

A permeabilidade entre acontecimentos da vida pessoal e cultural e decisões na esfera profissional são representadas: (a) na escolha vocacional para o exercício da psicoterapia e (b) na escolha dos modelos, problemáticas e populações preferenciais de intervenção.

$\mathrm{Na}$ escolha vocacional para o exercício da psicoterapia, foram citadas experiências promotoras de reflexão e questionamento promovidas no contexto de pares e de familiares bem como acontecimentos que desencadearam crises pessoais, tais como ruturas relacionais e perdas subjacentes ao interesse pelas motivações e compreensão do comportamento humano:

Eu tive uma fase de crise pessoal, em que estive muito mal, muito deprimido, com um corte relacional, enfim, foi uma fase complicada para mim, foi uma fase de questionamento, e, de repente, acho que comecei a ficar fascinado como é que as pessoas funcionavam (c1m).

A Revolução de Abril $^{2}$ foi também avaliada como contexto cultural e político criativo e potenciador de interrogações, debates e preocupações de intervenção social, e é representada por alguns psicoterapeutas como contexto favorável à emergência do interesse nas ciências sociais e humanas.

Foram também descritas experiên-cias no contexto pessoal que tiveram impacto na escolha dos modelos teóricos, das problemáticas e das populações de intervenção. Um psicoterapeuta descreve o impacto do nascimento da filha na sua disponibilidade para continuar a atender crianças em um registo mais analógico $(\mathrm{c} 1 \mathrm{~m})$, e outro fala-nos sobre a relação entre a morte do pai e o seu interesse por problemáticas no domínio existencial (cc3m).

\subsection{Implicações na relação psicoterapêutica}

É também sinalizado o impacto que determinadas experiências de vida tiveram na construção e no significado da relação terapêutica, nomeadamente no que se refere à (a) empatia:

Coisas da minha vida que me aconteceram também me levaram a estar de outra forma, uma coisa é a empatia que nós tentamos todos ter, outra coisa é aquilo que sentimos a partir de experiências que também já vivemos, e, com a idade e com o tempo, a vida vai-nos trazendo coisas que nos ajudam a perceber melhor o mundo dos outros (h3m)

É descrito também o impacto que experiências dramáticas e dificuldades sentidas, em especial no âmbito conjugal e familiar, têm na disponibilidade para a prática e para a relação psicoterapêutica, principalmente na capacidade de (b) devolver esperança. $\mathrm{Na}$ seguinte transcrição, uma psicoterapeuta descreve como a vivência de tragédias na sua infância se reflete na sua forma de transmitir esperança aos seus clientes:

Passei por várias tragédias, tragédias, mesmo, na vida, se calhar, o facto de ter conseguido sempre lidar de uma forma mais construtiva, ou mais positiva, e com o tal sorriso, acho que isso também depois se traduz, quando estou a assistir aos outros no sofrimento deles (...) as minhas competências, as minhas forças, servemme também para entender os outros, para ir à descoberta das competências e das forças nos outros e, se calhar, para ser mais convicta na transmissão dessas forças e dessas competências (s1f)

História core - desenvolvimento do psicoterapeuta: diálogo e coerência entre self pessoal e profissional

O tema organizador ou história core transversal nas entrevistas é o desenvolvimento do psicoterapeuta como processo progressivo de 
procura de coerência entre as experiências da vivência pessoal e profissional. O desenvolvimento profissional do psicoterapeuta encontra-se intimamente relacionado com a sua construção como pessoa. Esta parece ser a representação mais explicitada pelos psicoterapeutas entrevistados acerca do seu desenvolvimento profissional:

Eu não vejo a psicoterapia como um ter, a psicoterapia é um ser, é um processo constitutivo, nós temos que respirar isso (...) porque também é o nosso próprio desenvolvimento pessoal, também somos nós próprios que também estamos muito em jogo nas coisas que temos dentro de nós próprios, naquilo que somos, na compreensão daquilo que somos e na utilização dessa mesma compreensão (p1m)

O psicoterapeuta é um profissional da relação, e, como afirma uma psicoterapeuta, é "uma questão de investigação fundamental conhecer os próprios psicoterapeutas, porque nós somos o principal instrumento do nosso trabalho" (cc1f), instrumento esse com histórias relacionais, com memórias, construções de realidades, significados, com idiossincrasias que estão presentes na forma como se é psicoterapeuta.

O desenvolvimento do psicoterapeuta não se inscreve exclusivamente no plano profissional de desenvolvimento de competências técnicas para o exercício da prática, mas remete ao domínio do autoconhecimento e da aceitação de características pessoais como importantes recursos para a definição de uma prática personalizada de intervenção psicoterapêutica. O autoconhecimento e a aceitação de si são mesmo considerados fatores relevantes na aceitação e na compreensão do outro: "se a pessoa não se consegue conhecer bem, dificilmente consegue conhecer os outros, e, se não consegue conhecer os outros, dificilmente é empática" (s1f). Um dos psicoterapeutas fala-nos também sobre o autoconhecimento presente na capacidade de leitura das ressonâncias do que o cliente transmite para o processo psicoterapêutico:

Leio melhor o desconforto de um modo relacional, isto é, quando me sinto desconfortável, em vez de achar que sou eu que sou inadequado, que eu podia ser melhor psicoterapeuta, penso 'por que é que eu estou a sentir isso, por que é que esta pessoa me está a fazer sentir (...) ...por que é que é que a relação com essa pessoa me está a fazer sentir desconfortável, o que é que ela me está a dizer?'(c1m)

A síntese e a integração de experiências no domínio pessoal e profissional do psicoterapeuta sugerem a progressiva personalização do papel e das características consideradas importantes na prática psicoterapêutica. A construção de um estilo pessoal de intervenção e a legitimação da pessoa do psicoterapeuta constituem marcadores centrais do seu processo maturativo e desenvolvimental:

Eu sou muito mais eu do que era no passado (...) e, portanto, o meu bem-estar passou a ser legitimado na relação. A minha experiência pessoal passou a ser legitimada, a pessoa que eu sou passou a ser legitimada (c2m)

O processo desenvolvimental do psicoterapeuta é representado como um processo ao longo da vida e da experiência refletida da prática, visto actualizar-se na diferença que a compreensão do outro exige. E são precisamente a curiosidade, a abertura à experiência fenomenológica do outro e o fascínio subjacente à compreensão da complexidade e da singularidade humanas os lubrificantes primordiais da engrenagem dinâmica e inacabada do desenvolvimento do psicoterapeuta. Tal como ressalta um psicoterapeuta:

A psicoterapia é um fenómeno de humanidade (...) o ser-se psicoterapeuta é um caminho, e é um caminho que nunca 
está, nem nunca será, acabado, nunca será terminado, é um caminho que se vai fazendo ao longo da experiência, ao longo da vida (p1m)

\section{Discussão dos resultados e implicações do estudo}

(...) É imprescindível uma reflexão adequada sobre a pessoa do psicoterapeuta, pois ele é mais importante como pessoa que o método ou sistema que utiliza. É mais significativo o que faz, transmite e vive que as técnicas ou a visão filosófica em que se fundamenta. O resultado e a eficiência da psicoterapia dependerão muito da grandeza e amplidão de sua personalidade (Ribeiro, 1986, pp.15-16)

O objetivo do presente estudo foi analisar as representações e significações de 20 psicoterapeutas reconhecidos (peritos) de diferentes orientações teóricas e práticas acerca das experiências e dos momentos que consideraram determinantes no seu desenvolvimento profissional. Neste estudo, no entanto, não se procurou desenhar as trajetórias desenvolvimentais do psicoterapeuta, mas analisar a diversidade de experiências que ocorrem no espaço terapêutico e extraterapêutico que contribuem para a construção do que é o ser psicoterapeuta. As experiências representadas pelos psicoterapeutas como as mais passíveis de promover mudança e desenvolvimento surgem no contexto de dimensões interpessoais da existência do psicoterapeuta, quer no contexto de relações psicoterapêuticas, quer no contexto de relações pessoais. Esses dados são consistentes com o estudo de Skovholt e Rønnestad (1995), que afirmam que experiências interpessoais parecem ser mais importantes do que fontes impessoais de informação tais como seminários, teorias e trabalhos desenvolvidos. Também no estudo internacional de Orlisnky e Rønnestad (2005) a experiência clínica com clientes é considerada a mais determinante no desenvolvimento do psicoterapeuta, seguindo-se a psicoterapia pessoal, a supervisão, os cursos e seminários e as experiências na vida pessoal. Tal constatação não invalida, no entanto, a importância incontornável de uma formação teórica e uma supervisão de qualidade no desenvolvimento dos psicoterapeutas e na própria qualidade de intervenção com os clientes.

Relativamente ao primeiro subtema analisado, experiências relacionais no domínio profissional que contribuíram para o desenvolvimento do psicoterapeuta, verificamos que são as experiências com um tónus emocional mais intenso que representaram momentos significativos no seu desenvolvimento. Por um lado, verificamos que são representadas como experiências que têm impacto positivo e reforçador da prática o sentido de gratificação, o acesso a dimensões privilegiadas da vivência do cliente e a natureza da ligação emocional que esses profissionais desenvolvem com alguns clientes, como experiências que Ihe devolvem o sentido de utilidade e de eficácia da sua prática. Por outro, o sentido de incapacidade de ajuda, as desistências inesperadas de clientes, as dificuldades em estabelecer a relação terapêutica, a gestão dos limites da psicoterapia e o desgaste emocional provocado pela prática parecem constituir desafios desenvolvimentais que poderão suscitar o abandono precoce da atividade ou mesmo o burnout do psicoterapeuta. Os profissionais da saúde mental são considerados especialmente suscetíveis à síndrome de burnout (Abreu, Stoll, Ramos, Baumgmart, \& Kristensen, 2002; Dlugos \& Friedlander, 2001). Os resultados encontrados no presente estudo são corroborados por investigações que sublinham, como fatores de risco para o burnout dos psicoterapeutas, o sentido de não gratificação, a inexistência de melhorias dos clientes, o desgaste provocado pela exposição ao sofrimento humano e ao sobre-envolvimento emocional (e.g. Farber 
\& Heifetz, 1982; Hellman, Morrison, \& Abramowitz, 1986).

A prática refletida e acumulada parece também ser representada como importante dispositivo para a validação dos fatores determinantes no processo de psicoterapia. A leitura colaborativa do processo terapêutico, a importância da qualidade da relação terapêutica e a pragmática de ajuda, processo que Rønnestad e Skovholt (2003) designam desenvolvimento do conhecimento sensível ao contexto, parecem ser três das características identificadas por Skovholt e Jennings (2004) e por Rønnestad e Skovholt (2003) em psicoterapeutas peritos. Sendo a psicoterapia uma arte (Gomes, 1995), um encontro dialógico entre as realidades do psicoterapeuta e do cliente, não é surpreendente que o espelho deste último constitua o maior reflexo da prática exercida pelo profissional, e são precisamente a compreensão e a integração dos encontros e dos desencontros desses momentos os catalizadores centrais de um sentido do ser e estar em psicoterapia.

No que se refere ao segundo subtema abordado, verificamos que experiências relacionais no domínio pessoal tiveram implicações na escolha vocacional para o exercício da psicoterapia, na escolha dos modelos, problemáticas, populações preferenciais de intervenção e na construção e no significado da relação terapêutica, nomeadamente no que se refere à empatia e à devolução de esperança aos clientes. No estudo de Rønnestad e Skovholt (2003), os autores verificaram que psicoterapeutas mais experientes relatavam maior impacto de experiências da vida pessoal na prática profissional. No mesmo estudo, os autores constataram que experiências com um tonus emocional negativo, como histórias de abandono e contextos familiares rígidos e exigentes, parecem ser mais marcantes do ponto de vista das implicações para a prática. Apesar de no presente estudo os psicoterapeutas não enunciarem explicitamente os acontecimentos de vida com implicações para a prática, nomeadamente experiências de carácter mais negativo, verificamos que, no que se refere a acontecimentos de vida geradores de maior stress emocional, estes são atualmente potenciados na prática psicoterapêutica e sentidos como mais-valias no que se refere à empatia e à prestação de apoio. Essas experiências remetem-nos para o conceito de Henry (1966) de wounded healer ou curador ferido, segundo o qual as feridas de estádios iniciais de desenvolvimento do psicoterapeuta contribuíam para a prestação de ajuda mais eficaz. Outros estudos sublinham a necessidade de reflexão, compreensão e integração dessas feridas para um desempenho mais efetivo na ajuda psicoterapêutica (Stiles, 1997). O estudo internacional de desenvolvimento dos psicoterapeutas também nos remete para essa permeabilidade entre a sua história de vida pessoal e a sua prática, visto terem sido encontradas relações entre a qualidade dos cuidados na infância e o desempenho profissional. Essa relação, porém, é moderada pela sua psicoterapia pessoal (Orlinsky \& Rønnestad, 2005; Orlinsky et al., 1999), visto esta constituir-se enquanto oportunidade privilegiada para o autoconhecimento e para a compreensão das implicações das características do psicoterapeuta na compreensão e na leitura do outro. Segundo Boris (2008, p.167), “para o terapeuta, não há melhor introdução à variedade do sofrimento humano do que a descoberta de que, em algum canto de seus pensamentos, ele pode encontrar palavras, lembranças, razões, visões e pensamentos parecidos com aqueles que afetam, agitam ou mesmo enlouquecem seus pacientes". É precisamente esse "canto dos pensamentos" a história que antecede e acompanha o ser psicoterapeuta-pessoa e que constitui um desafio à compreensão da leitura das características que os psicoterapeutas usam e potenciam na sua prática profissional. 
Rogers (1975), no seu artigo ironicamente intitulado Empathic: an unappreciated way of being, destaca que, "quanto mais integrado o psicoterapeuta se sentir consigo mesmo, maior o grau de empatia que exibe" (com os clientes) (p.4). O ser e tornar-se psicoterapeuta é um processo que ultrapassa o domínio dos modelos teóricos, das técnicas e da leitura conceptual da psicoterapia, normalmente privilegiada nos estudos comparativos (Reupert, 2006), e inscrevese em um domínio mais complexo de crescente diferenciação e de personalização da prática. Dessa forma, esse processo é representado pelos participantes como contínuo, inacabado, na medida em que se desenha na dialética entre experiências psicoterapêuticas e extrapsicoterapêuticas, sendo a própria definição de psicoterapia, de mudança terapêutica, de relação de ajuda e do papel do psicoterapeuta inerente à história do desenvolvimento desse profissional. Parece-nos, assim, que a contínua procura de uma coerência entre o que são os desafios relacionais da prática e os da vivência pessoal do psicoterapeuta deverá ser objeto de uma compreensão mais aprofundada, dadas as implicações da mesma na representação da qualidade das práticas psicoterapêuticas.

Uma primeira implicação deste estudo prende-se com a importância de relevar, no decurso do treino, da formação e da supervisão dos psicoterapeutas, a componente socioafectiva do seu desenvolvimento. Devido à natureza desafiante das experiências psicoterapêuticas, esta poderá, por um lado, revelar-se desenvolvimental e potenciadora de níveis de complexificação crescente quando da integração das aprendizagens, e por outro, poderá comportar riscos, dada a vivência vicariante de situações dramáticas e as exigências pessoais. A integração, no currículo de profissionais de psicoterapia, de experiências que promovam a reflexão da prática, o autoconhecimento e a integração de experiências pessoais, para que estas sejam compreendidas quando projetadas e o auxiliem na gestão emocional de experiências psicoterapêuticas, constitui um desafio central da humanização do ensino do psicoterapeuta. Já Freud, em 1910/1978, reconhecia que "nenhum psicanalista poderia ir mais além do que o permitido pelos seus próprios complexos e resistências internas" (p.145). A psicoterapia será sempre um encontro de duas ou mais leituras do self, do mundo e dos outros, e, como diria Mahoney (1998), as nossas escolhas não são nem aleatórias, nem irrelevantes, e seremos sábios ao examinarmos os padrões e as preferências das nossas próprias opções. Tal envolve a compreensão, tanto quanto possível, das implicações dos significados do psicoterapeuta sob a forma como percebe o cliente e todo o processo psicoterapêutico. Assim, parece-nos ser importante, na formação dos psicoterapeutas, atender às suas idiossincrasias e vivências e promover o desenvolvimento de competências relacionais que potenciem o trabalho terapêutico.

Uma segunda implicaçãosublinhaa importância de relevar, no estudo, a humanização do psicoterapeuta, nomeadamente no que se refere à necessidade de aprofundarmos o impacto que a sua história pessoal e relacional tem na forma como personaliza a sua prática e dá significado ao seu papel. A introdução de características pessoais como variáveis importantes da forma de ser e de tornar-se psicoterapeuta poderão ajudar a compreender as interações complexas que se estabelecem entre profissional e cliente, quer em uma abordagem de investigação dos processos, quer dos resultados. A forma como os psicoterapeutas veem as suas relações pessoais e de vinculação, como regulam as suas emoções, como percecionam as suas competências relacionais, a satisfação em contextos relacionais mais significativos e o seu sentido de self poderão ser tópicos importantes na investigação mais aprofundada 
do impacto da qualidade das experiências relacionais e dos acontecimentos na vivência pessoal na forma de ser e de tornar-se psicoterapeuta.

Os resultados do presente estudo devem ser analisados à luz de várias limitações. A primeira reside no facto de que, devido à natureza qualitativa do estudo exploratório apresentado, os dados não poderão ser generalizados a outros psicoterapeutas senão de forma teórica e hipotética. A segunda limitação prende-se com processo de identificação da amostra de nomeação por pares, na medida em que, apesar de procurarmos minimizar o efeito do conhecimento institucional dos psicoterapeutas, ao reunirmos o consenso entre nove profissionais de diferentes pontos geográficos do país, esta não é considerada uma amostra representativa de psicoterapeutas experts (peritos) em Portugal.

\section{Helena Moura de Carvalho}

Este artigo foi realizado no âmbito da bolsa de doutoramento (SFRH/BD/22333/2005) e do projecto “Vinculação, desenvolvimento e adaptação psicossocial" (PTDC/PSI/65416/2006) suportados pela Fundação para a Ciência e Tecnologia-Portugal.

Licenciatura (a terminar doutoramento), Psicóloga e investigadora do Centro de Psicologia da Universidade do Porto, Portugal.

E-mail: helena.mrmc@gmail.com

\section{Paula Mena Matos}

Psicóloga, Investigadora do Centro de Psicologia da Universidade do Porto e Professora Auxiliar da Faculdade de Psicologia e de Ciências da Educação da Universidade do Porto, PORTUGAL. (estudante de doutoramento)

E-mail: pmmatos@fpce.up.pt

Endereço para envio de correspondência:

Faculdade de Psicologia e de Ciências da Educação da Universidade do Porto, Rua do Dr. Manuel Pereira da Silva, Porto, Portugal CEP 4200-392.

Recebido 28/10/2009, 1a Reformulação 17/5/2010, Aprovado 7/6/2010

\section{Referências}

Ahn, H., \& Wampold, B. E. (2001). Where or where are the specific ingredients? A meta-analysis of component studies in counseling and psychotherapy. Journal of Counseling Psychology, 48, 251-257.

Abreu, K. L., Stoll, I., Ramos, L. S., Baumgardt, R. A., \& Kristensen, C. H. (2002). Estresse ocupacional e síndrome de burnout no exercício profissional da psicologia. Psicologia: Ciência e Profissão, 22, 22-29.

Atwood, G. E., \& Stolorow, R. D. (1993). Faces in a cloud: Intersubjectivity in personality theory. Northvale, New Jersey: Jason Aronson.

Beutler, L. E., Malik, M., Alimohamed, S., Harwood, T. M., Talebi, H., Noble, S., \& Wong, E. (2004). Therapist variables. In M. J. Lambert (Ed.), Bergin and Garfield's handbook of psychotherapy and behavior change (5th ed. pp. 227-306). New York: Wiley.

Black, S., Hardy, G., Turpin, G., \& Parry, G. (2005). Self-reported attachment styles and therapeutic orientation of therapists and their relationship with reported general alliance quality and problems in therapy. Professional Psychology: Research and Practice, 78, 363-377.
Boris, G. D. J. B. (2008). Versões de sentido: um instrumento fenomenológico-existencial para a supervisão de psicoterapeutas iniciantes. Psicologia Clínica, 20(1), 165-180.

Carvalho, H., \& Matos, P. M. (2006). Entrevista sobre o psicoterapeuta. Manuscrito não publicado.

Castonguay, L. G., Goldstein, M. R., Wiser, S., Raue, P. J., \& Hayes, A. M. (1996). Predicting the effect of cognitive therapy for depression: A study of unique and common factors. Journal of Consulting and Clinical Psychology, 64, 497-504.

Charmaz, K. (2000). Grounded theory: Objectivist and constructivist methods. In N. Denzin, \& Y. Lincoln (Eds.), Handbook of qualitative research (2nd ed. pp. 509-535). Thousand Oaks CA: Sage.

Chasen, B. (1996). Death of a psychoanalyst's child. In B. Gerson (Ed.), The therapist as a person: Life crises, life choices, life experiences, and their effects on treatment (pp. 3-20). Hillsdale, NJ: The Analytic Press.

Eysenck, H. J. (1952/1992). The effects of psychotherapy: An evaluation. Journal of Consulting \& Clinical Psychology, 60, 659-664. (Trabalho original publicado em 1952) 
Dlugos, R. F., \& Friedlander, M. L. (2001). Passionately committed psychotherapists: A qualitative study of their experiences. Professional Psychology: Research and Practice, 32(3), 298-304

Farber, B. A., \& Heifetz, L. J. (1982). The process and dimensions of burnout in psychotherapists. Professional Psychology: Research and Practice, 13(2), 293- 301.

Fernandez-Álvarez, H., Garcia, F., LoBianco, J., \& Corbella, S. (2003). Assessment Questionnaire on the Personal Style of the Therapist PST-Q. Clinical Psychology and Psychotherapy, $10,116-125$

Freud, S. (1910/1978). The future prospects of psycho-analytic therapy. In J. Strachey (Ed.), The Standard Edition of the Complete Psychological Works of Sigmund Freud (Vol. 11, pp). London: Hogarth. (Trabalho original publicado em 1910)

Glaser, B. G., \& Strauss, A. L. (1967). The discovery of grounded theory: Strategies for qualitative research. New York: Aldine.

Gomes, W. B. (1995). A relevância da pesquisa na formação do psicoterapeuta: autonomia e qualificação profissional. Temas em Psicologia: Ensino, Formação e Orientação, 1, 83-93.

Hellman, I. D., Morrison, T. L., \& Abramowitz, S. I. (1986). The stresses of psychotherapeutic work: A replication and extension. Journal of Clinical Psychology, 42(1), 197-205.

Henry, W. E. (1966). Some observations on the lives of healers. Human Development, 9, 47-56.

Jennings, L., \& Skovholt, T. M. (1999). The cognitive, emotional, and relational characteristics of master therapists. Journal of Counseling Psychology, 46, 3-11.

Krause, M. S., \& Lutz, W. (2009). Process transforms inputs to determine outcomes: Therapists are responsible for managing process. Clinical Psychology: Science and Practice, 16, 73-81.

Magalhães, I. (2008). No trilho do jovem psicoterapeuta: um estudo qualitativo. Tese de mestrado, Faculdade de Psicologia e de Ciências da Educação, Universidade do Porto.

Mahoney, M. J. (1998). Processos humanos de mudanças: as bases científicas da psicoterapia (F. Appolinário, Trad.). Porto Alegre: Artmed.

Orlinsky, D. E., \& Ronnestad, M. H. (2005). How psychotherapists develop: A study of therapeutic work and professional growth. Washington DC: APA.

Orlinsky, D. E., Ambuehl, H., Ronnestad, M. H., Davis, J., Garin, P., Willutzi, U., Bottermans, J. E., Dazord, A., Cierpka, M., Aapro, N., Buchhein, P., Bae, S., Davidson, C., FriisJorgensen, E., Kalmykova, E., Meyerberg, J., Northcut, T., Parks, B., Scherb, E., Shroder, T., Sheller, G., Stiwne, D., Stuart, S., Tarragona, M., Vasco, A. B., \& Wiseman, H. (1999). Development of psychotherapists: Concepts, questions, and methods of a collaborative international study. Psychotherapy Research, 9, 127-153.

Patton, M. Q. (1990). Qualitative evaluation and research methods (2nd ed.). Newbury Park, CA: Sage Publications.

Radeke J. T., \& Mahoney, M. J. (2000). Comparing the personal lives of therapists and research psychologists. Professional Psychology: Research and Practice, 31, 82-84.

Reupert, A. (2006). The counsellor's self in therapy: An inevitable presence. International Journal for the Advancement of Counselling, 28, 95-105.

Ribeiro, J. P. (1986). Teorias e técnicas psicoterápicas. Petrópolis, RJ: Vozes.

Rønnestad, M. H., \& Skovholt, T. M. (2003). The journey of the counselor and therapist: Research findings and perspectives on development. Journal of Career Development, 30(1), 5-44.

Rogers, C. R. (1975). Empathy: An unappreciated way of being. The Counselling Psychologist, 5, 2-10.

Sauer, E. M., Lopez, F. G., \& Gormley, B. (2003) Respective contributions of therapist and client adult attachment orientations to the development of the early working alliance: A preliminary growth modeling study. Psychotherapy Research, 13, 371-382.

Skovholt, T. M., \& Rønnestad, M. H. (1995). The evolving professional self: Stages and themes in therapist and counselor development. Chichester, England: Wiley.

Skovholt, T. M., \& Rønnestad, M. H. (2003). The hope and promise of life-span counselor and therapist development. Journal of Career Development, 30, 1-3.

Skovholt, T. M., \& Jennings, L. (2004). Master therapists: Exploring expertise in therapy and counseling. Boston: Allyn \& Bacon.

Stern, P. N. (1980). Grounded theory methodology: Its uses and processes. Image, 12, 20-23.

Stiles, W. (1997). Multiple voices in psychotherapy clients. Journal of Psychotherapy Integration, 7, 177-180.

Strauss, A., \& Corbin, J. (1990). Basics of qualitative research Grounded theory procedures and techniques. Newbury Park, California: Sage Publications.

Vasco, A. B. (1992). Psicoterapeuta, conhece-te a ti próprio. características, crenças metateóricas, estilos psicoterapêuticos e desenvolvimento epistemológico dos psicoterapeutas portugueses. Tese doutorado, Faculdade de Psicologia e de Ciências da Educação da Universidade de Lisboa. Lisboa.

Vasco, A., \& Dryden, W. (1997). Does development do the did? Clinical experience and epistemological development together account for similarities in therapeutic style. Psychotherapy, $34,262-271$.

Vasco, A. B., \& Dryden, W. (1994). The development of psychotherapists' theoretical orientation and clinical practice. British Journal of Guidance and Counselling, 22, 327-341.

Wampold, B. E. (2001). The great psychotherapy debate: Models, methods, and findings. New Jersey: Lawrence Erlbaum.

Wilson, J. E. (1993). Towards a personal model of counselling In W. Dryden (Ed.), Questions and answers on counselling in action (pp. 95-102). London: Sage. 